\title{
Limb-Girdle Muscular Dystrophy-A Case Report
}

Krishna Kumar Dhakchinamoorthi ${ }^{{ }^{*}}$, Yemimah Elizabeth Shaji ${ }^{2}$, Ann Mariya Jose ${ }^{2}$, Rheya Mathew ${ }^{2}$, Sanaj Varghese ${ }^{2}$, Dorathi Ria Monisha $\mathrm{A}^{2}$

${ }^{1}$ Professor and Head, ${ }^{2}$ Pharm.D Interns, Department of Pharmacy Practice, Pharm.D, C.L. Baid Metha College of Pharmacy, Chennai, India

DOI: $10.36347 /$ simcr.2020.v08i11.010

| Received: 06.11.2020 | Accepted: 17.11.2020 | Published: 20.11.2020

*Corresponding author: Dr. Krishna Kumar Dhakchinamoorthi

Abstract

Limb-Girdle Muscular Dystrophy (LGMD) is a group of skeletal muscle disorder characterized by muscle weakness in the upper and lower limbs, elevated creatine phosphokinase and decreased muscular activity. The disorder occurs due to the genetic variability among the genes involved in synthesis of muscle protiens. The most commonly affected muscular protein is dystrophin encoded by the dystrophin gene located in the human X chromosome. LGMD subgrouped as sarcoglycanopathies, dysferlinopathy, calpainopathy, and GNE myopathy based on the protein and genetic involvement. In the present case report a 34 years old male admitted with complaints of lower limb weakness with elevated creatine phosphokinase (CPK) and found to be $2647.7 \mathrm{U} / \mathrm{L}$ (24-195 U/L). Also, serum lactate dehydrogenase was found to be $304 \mathrm{U} / \mathrm{L}$. Also he was treated for the complication of grade I fatty liver. In the present case, regular monitoring and symptomatic management required to prevent or reduce the risk of other signs and symptoms.

Keywords: Limb-Girdle Muscular Dystrophy (LGMD), muscle weakness, dysferlinopathy, calpainopathy. Copyright $(\odot) 2020$ The Author(s): This is an open-access article distributed under the terms of the Creative Commons Attribution 4.0 International License (CC BY-NC 4.0) which permits unrestricted use, distribution, and reproduction in any medium for non-commercial use provided the original author and source are credited.

\section{INTRODUCTION}

Muscular dystrophy (MD) is a complex disorder manifested by skeletal muscle destruction and inactivity. It is a group of geneticaly inherited disorders that weakens the muscle progressively over time. It affects any age but mostly occurs in the first decade of life [1]. The cause of muscular dystrophy is genetic variability in several genes. There are many types, however, classified into nine major classes, Duchenne, Myotonic, Becker, Congenital, Facioscapulohumeral, Limb-girdle, Oculopharyngeal, Distal, and EmeryDreyfuss dystrophy [2]. It was reported that fatal muscle-wasting disorder affecting 1 in 3,500 males born with genetic variation and inherited as familial $\mathrm{X}$ linked disorder, either dominant or recessive [3]. The mutation or variation occurs spontaneously during the replication of DNA and leads to a spontaneous rupture in the DNA bases. It leads to defective protein-coding and synthesis. The most commonly affected muscular protein is dystrophin encoded by the dystrophin gene located in the human $\mathrm{X}$ chromosome. The most commonly reported symptoms were limb weakness of the pelvic or shoulder girdles. At the molecular level, all the muscular dystrophy affects the cytoskeleton, damage the muscle sarcolemma, resulting in gradual muscular damage [4, 5]. Limb-girdle muscular dystrophy (LGMD) is commonly reported in India [6]. LGMD affects all four limbs and causes weakness, also causes myopathies with proximal weakness, it affects any age but mostly occurs in children [7]. The cause of LGMD is genetic variability in several genes [8]. It is mainly diagnosed by genotype and phenotype finding however it depends mainly on genetic testing with phenotype findings include high creatine kinase level, electromyography, and myopathy pattern and also by muscle biopsy. Most confirming methods for detecting LGMD are immunoblot analysis followed by genetic testing [8]. The high expenditure for these methods limits the diagnosis and identification of LGMD.

\section{Case Report}

A 34 years old male admitted with complaints of lower limb weakness. Later he had developed upper limb weakness. Symptoms were progressive for the past one year. He could not stand and not able to walk for the past one year. He was diagnosed with limb-girdle muscular dystrophy (LGMD) confirmed by muscle biopsy. On examination he was conscious, oriented, no nystagmus moves all four limbs, obeys commands, no drift, no facial asymmetry, no ataxia, sensation found normal, power also found normal. His vital sign examination revealed that pulse rate $78 / \mathrm{min}$, blood pressure $110 / 70 \mathrm{mmHg}$, respiratory rate $18 / \mathrm{min}$, and 
$\mathrm{SPO}_{2} 99 \%$. Systemic examination was found normal. His manul muscle testing charting was noted (Table-1).

Table-1: Manual Muscle Testing (MMT) Score

\begin{tabular}{|l|l|l|}
\hline Upper limb shoulder & Right & Left \\
\hline Flexin & $2 / 5$ & $2 / 5$ \\
\hline Extension & $2 / 5$ & $2 / 5$ \\
\hline Abduction & $2 / 5$ & $2 / 5$ \\
\hline adduction & $2 / 5$ & $2 / 5$ \\
\hline Upper limb Elbow & Right & Left \\
\hline Flexin & $3 / 5$ & $2 / 5$ \\
\hline Extension & $3 / 5$ & $3 / 5$ \\
\hline Upper limb Wrist & Right & Left \\
\hline Distal & $4 / 5$ & $4 / 5$ \\
\hline Proximal & $4 / 5$ & $4 / 5$ \\
\hline Lower limb Knee & Right & Left \\
\hline Flexin & $1 / 5$ & $1 / 5$ \\
\hline Extension & $2 / 5$ & $2 / 5$ \\
\hline Lower limb (Hip) & Right & Left \\
\hline Flexin & $2 / 5$ & $2 / 5$ \\
\hline Extension & $2 / 5$ & $2 / 5$ \\
\hline Abduction & $2 / 5$ & $2 / 5$ \\
\hline adduction & $1 / 5$ & $1 / 5$ \\
\hline Lower limb (Ankle) & Right & Left \\
\hline Dorsi flexion & $2 / 5$ & $2 / 5$ \\
\hline Plantor flexion & $3 / 5$ & $3 / 5$ \\
\hline & &
\end{tabular}

\section{Investigation}

Creatine phosphokinase (CPK) was highly elevated and found to be $2647.7 \mathrm{U} / \mathrm{L}$ (24-195 U/L). Also, serum lactate dehydrogenase was found to be 304 $\mathrm{U} / \mathrm{L}$ (normal range 10-246 U/L). The thyroid function test was shown all values within the normal range (Triiodothyronine (T3)-98.6 ng/dl, Thyronine (T4)6.42ul, free T3- $3.00 \mathrm{pg} / \mathrm{ml}$, free $\mathrm{T} 4-1.20 \mathrm{ng} / \mathrm{dl}$, Thyroid-stimulating hormone (TSH)-4.0 mU/L). Pulmonary function test revealed that percentage prediction of FVC-53\%, FEV1- 55\%, FEV1/FVC$106 \%$, PEFR- 52\%, FEF $25-75^{-}$54\%. Ultrasound scan test (USG) abdomen was done which showed grade I Fatty liver, no other significant abnormality detected. ECHO cardiography was done which showed that LVEF $61 \%$. No pericardial effusion or thrombosis. All values are structurally normal.

Patient reviewed on examination he was conscious, oriented, obeys commands, and moves his limbs, advised to continue the physiotherapy. Further, he was confirmed with muscular weakness, but no deficit, however on day four he was found with grade I fatty liver. Further, he was neurologically normal and on discharge all his vital signs were normal. During admission the patient was managed with tablet lorazepam $0.5 \mathrm{mg}$ once daily, tablet paracetamol 650 $\mathrm{mg}$ once daily, tablet L.carnitine twice daily, capsule CO-Q $300 \mathrm{mg}$ once daily, and tablet ubicar, twice daily and advised to continue until review.

\section{Discussion}

In the present case, he was diagnosed as LGMD by muscle biopsy and phenotype examination. However, recently admitted for the complaints of his upper limb weakness. The laboratory investigation shows that his serum creatine kinase and lactate dehydrogenase levels were highly veried than normal. These levels are considered phenotype variations and confirming muscular dystrophy. The patient was investigated for other organ involvement and tested for various tests including thyroid function tests, pulmonary function test, cardiac function tests shows normal functioning however the liver function tests shows that he had diagnosed with grade I fatty liver. It was managed with hepato-protective agents. The patient was examined by manual muscle testing and found with poor muscular activity in the upper and lower limbs. The manual muscle testing scores were observed similar to previous reports [9]. In the present case, the disease progression observed slow, however, in most of the cases the severity improved during their 30 to 40 years, with proper medical management and care the survival rate could be increased.

In previous studies reported that the prevalence of limb-girdle muscular dystrophy varied among the different population with their clinical manifestations, in a recent meta-analysis, it was reported that 16.14 per 100000 populations. Based on the presence of clinical features 8.26 myotonic dystrophy, 3.95 had facioscapulohumeral dystrophy, 1.63 had limb-girdle muscular dystrophy and 0.99 had congenital muscular dystrophies [8]. Mainly LGMD grouped based on their clinical features, however, the disease is named or diagnosed based on the gene involvement (sarcoglycanopathies, dysferlinopathy, calpainopathy, and GNE myopathy). The major subclass of LGMD is classified based on the autosomal dominant LGMD1 and autosomal recessive LGMD2. Among them, dysferlinopathy, sarcoglycanopathies (14\%), and calpainopathies $(10 \%)$ had been reported most commonly in the Asian and Indian population. Further, dysferlinopathy labeled into two common clinical entities as proximal onset LGMD2 and distal onset Miyoshi myopathy [10]. The first autosomal recessive LGMD (LGMD 2A) reported as Calpainopathy occurs as a result of defective calpain 3 protein resulting in calpain deficiency, caplin 3 encoded by the gene CAPN 3 [11]. Another autosomal dystrophy reported with symptoms similar to Duchene muscular dystrophy (DMD) is Sarcoglycanopathies, the severity of this disease seen during the first decade of life [11]. Both male and female patients had reported similar severity, however, in the female, the disease is silent carriers.

There is no exact cure for the LGMD group of disorders, hence management is challenging. Therapeutic management is aimed to reduce the problems based on clinical features, signs, and organ involvement. Also, the diagnosis of rare genetic disorders often is challenging. Most of the cases 
require, supportive therapy, regular monitoring of the systemic function, and proper counseling to the patient caretaker can be resulted in a better outcome and extend the patient's survival rate.

Recent research and developments focusing on the LGMD group of disorders with stem cell therapy are called regenerative medicine [12]. Several attempts and strategies were tried with different cell therapy in chronic muscular disorders using myogenic cells derived from various stem cells from bone marrow, embryonic tissues, and recently developed pluripotent stem cells. However, the challenge involved in all regenerative therapy is an immunological reaction in the host. Further, stem cell therapy requires immune modulation during therapy [13].

\section{CONCLUSION}

The present case describes autosomal recessive LGMD with elevated creatinine phosphokinase, manual muscle testing, and positive muscle biopsy. The patient was treated for the complication of grade I fatty liver and further required regular monitoring to prevent or reduce the risk of other signs and symptoms.

\section{ACKNOWLEDGEMENT}

The resident doctors, nursing staff, and technicians of Global Hospital are gratefully acknowledged.

\section{REFERENCES}

1. Angelini C. Neuromuscular disease. Diagnosis and discovery in limb-girdle muscular dystrophy. Nat Rev Neurol. 2016;12(1):6-8.

2. Lue YJ, Lin RF, Chen SS, Lu YM. Measurement of the functional status of patients with different types of muscular dystrophy. Kaohsiung J Med Sci. 2009;25(6):325-33.

3. Santos S, da Silva Pequeno AA, Pessoa A, Galvao $\mathrm{CR}$, de Medeiros JL, Mathias W. Increased prevalence of inherited neuromuscular disorders due to endogamy in Northeast Brazil: the need of community genetics services. J Community Genet. 2014;5(3):199-203.
4. Aoki M, Liu J, Richard I, Bashir R, Britton S, Keers SM. Genomic organization of the dysferlin gene and novel mutations in Miyoshi myopathy. Neurology. 2001;57(2):271-8.

5. Allen DG, Whitehead NP, Froehner SC. Absence of Dystrophin Disrupts Skeletal Muscle Signaling: Roles of $\mathrm{Ca} 2+$, Reactive Oxygen Species, and Nitric Oxide in the Development of Muscular Dystrophy. Physiol Rev. 2016;96(1):253-305.

6. Pathak P, Sharma MC, Sarkar C, Jha P, Suri V, Mohd H. Limb girdle muscular dystrophy type $2 \mathrm{~A}$ in India: a study based on semi-quantitative protein analysis, with clinical and histopathological correlation. Neurol India. 2010;58(4):549-54.

7. Angelini C, Bonifati DM. New therapies in muscular dystrophies. Neurol Sci. 2000;21(5 Suppl):S919-24.

8. Mah JK, Korngut L, Fiest KM, Dykeman J, Day LJ, Pringsheim T. A Systematic Review and Metaanalysis on the Epidemiology of the Muscular Dystrophies. Can J Neurol Sci. 2016;43(1):163-77.

9. Stubgen JP. Limb girdle muscular dystrophy: an interval study of weakness and functional impairment. J Clin Neuromuscul Dis. 2008;9(3):333-40.

10. Mahjneh I, Marconi G, Bushby K, Anderson LV, Tolvanen-Mahjneh H, Somer H. Dysferlinopathy (LGMD2B): a 23-year follow-up study of 10 patients homozygous for the same frameshifting dysferlin mutations. Neuromuscul Disord. 2001;11(1):20-6.

11. Khadilkar SV, Faldu HD, Patil SB, Singh R. Limb-girdle Muscular Dystrophies in India: A Review. Ann Indian Acad Neurol. 2017;20(2):8795.

12. Bushby K. Looking Forward to New Therapies: A Personal Perspective on the Translational Landscape for Muscular Dystrophies. J Neuromuscul Dis. 2015;2(s2):S83-S7.

13. Maffioletti SM, Noviello M, English K, Tedesco FS. Stem cell transplantation for muscular dystrophy: the challenge of immune response. Biomed Res Int. 2014;2014:964010. 